\title{
Models for Life Cycle Assessment: Review of Technical Assumptions in Collection and Transportation Processes
}

\author{
Boštjan VIMPOLŠEK, Borut JEREB, Tone Lerher, Andreja KUTNAR, Andrej LISEC
}

\begin{abstract}
Since the early 1990s, the life cycle assessment (LCA) has been used to quantify the environmental impacts. Due to substantial dissimilarities in results among different LCA waste models, the aim of this review is to analyse different LCA models. Technical assumptions in collection and transportation processes among the models in connection with lifecycle inventory $(\mathrm{LCl})$ databases of inputs and outputs have been compared and reviewed. The most important inputs and outputs in LCl have been analysed. The mechanistic LCA models have been found to operate with more substantial and broader inputs and outputs than deterministic models; therefore, they represent a detailed presentation and a more suitable basis for further calculations, e.g., life cycle costing (LCC) of waste management. Nevertheless, the analysed mechanistic models do not include determined important time consumptions - this was exposed and missing data provided. The final findings are that future LCA models should: (1) include alternative fuels for transportation and bioplastic materials for collection equipment, (2) use mechanistic principles, (3) build detailer LCl data bases, (4) be linked with LCC modelling, (5) use bottom-up approach calculations and provide both environmental and economical point of view.
\end{abstract}

Keywords: collection; LCA models; LCl; solid waste; transportation

\section{INTRODUCTION}

\subsection{Problem statement}

In the last decade of past century, industry's demand for fresh resources significantly increased due to population growth and the enormous production of goods; in the $21^{\text {st }}$ century, demand is only rising. The World Bank predicted that the request for food will increase by $50 \%$ by 2030; the International Energy Agency plans an increase in oil request of $1 \%$ a year between 2011 and 2030; UNESCO plans that total global water use will increase by $32 \%$ between 2000 and 2025 [1]. In line with demand, the costs of new resources are also increasing. It is expected that costs for food oils and meals will rise by $10-20 \%$ by 2030 , for crude oil by $5 \%$ and for metals and minerals by $5-10 \%$ by the same year [2]. To meet these demands, industry is attempting to move from a linear to a circular economy and use waste resources [3-5]. In 2016, the total waste generated in the EU28 by all economic activities and households amounted to 2,533 million tonnes (5,0 tonnes per inhabitant), which was the highest amount recorded for the EU28 [6]. Nevertheless, the acquisition, recovery, or disposal of such quantities of waste has non-negligible and different impacts on the environment. One of the best techniques being developed to assess the environmental impacts of waste management systems and the decision support of appropriate waste management treatment is the lifecycle assessment (LCA).

The LCA is an analytical tool for the systematic and objective evaluation of all the essential influences that a product, a service, or a subject has on the environment within its life cycle $[7,8]$. It is a tool dedicated to the comparison of different products or waste alternatives (e.g., reuse vs recycling or recycling vs incineration, etc.).Thus, it is a tool for sustainable development evaluation [e.g. 9, 10]. The LCA deals with environmental impacts throughout the life cycle of a product or service, from the gaining of raw materials, use and recovery (e.g. reuse, recycling, incineration with energy recovery) or disposal (e.g. incineration without energy recovery, landfill) (e.g., cradle-to-grave). According to the ISO 14000 environmental management standards (ISO 14040
[11] and 14044 [12]), the elemental model comprised in the LCA framework forms of: (1) goal and scope definition, (2) life cycle inventory analysis (LCI), (3) life cycle impact assessment (LCIA), and (4) interpretation (Fig. 1).

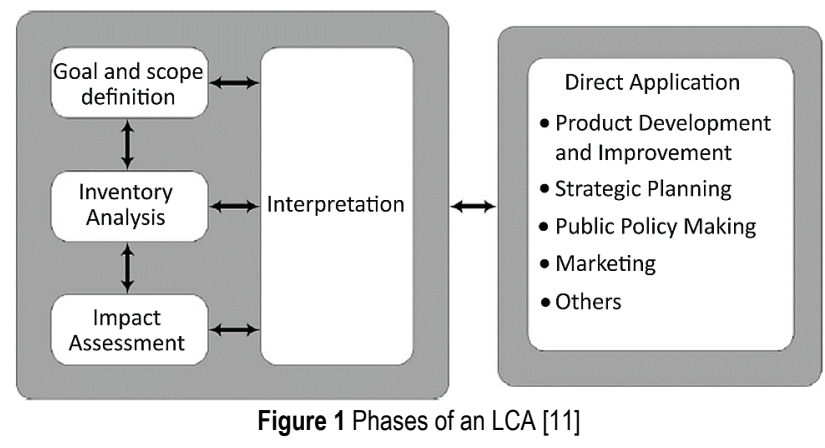

\subsection{Literature review of LCA modelling}

Currently, there are more than 222 published LCA studies of solid waste management systems $[13,14]$. These studies used different methodologies and tools. Among most used LCA tools are GaBi [15] and SimaPro [16], while environmental impact factors are mostly sourced from Ecoinvent database [17]. In this research, the core centre is on dedicated waste LCA tools for the evaluation of waste management systems.

Since the early 1990s, the literature in the field of services has included dedicated LCA models developed around the world. With these models, studies have been conducted on different fractions of materials [18, 19], or different management of waste treatment, e.g. collection and transportation [20], recycling [21, 19], incineration [18], or landfill. Currently, there are more than 50 models accessible in Europe, all on the base of the LCA [22]. The waste management models enable researchers and practitioners to use the LCA for their determined system without comprehensive know-how of the technique and allow them to study how changes in the system affect the biosphere impacts through different scenarios [23].

LCA models have also been included in a few review studies. Diaz \& Warith [24] estimated the GHG emissions 
from the city of Toronto for the period between 2001 and 2021, comparing three models. They determined that the models handle the emissions from waste transportation dissimilar. Some of the models reviewed were also found unsuitable due to using specialised software (e.g. Matlab) or allowing only restricted user modification of model parameters. In the comparative analysis of Winkler and Bilitewski [23], which was based on the quantitative assessment of municipal services, they compared models with the same input values. Similarly to the findings of Diaz and Warith [24], the compared models are very complicated, inflexible, hard to explain and, above all, inappropriate for everyday use. Furthermore, in the study, selected models provided very different and contradictory results. The comparative work has been continued by Gentil et al. [22], who reviewed and analysed nine different LCA models, showing how the various models learned and developed from prior while including new understanding, functionality and presenting why and from where differences among the models came.

\subsection{Objectives of the Research}

The aim of this research is to examine the use of the environmental impact assessment in the management of the waste. In this review the LCA analysis in different models was compared considering the technical assumptions, the type of technologies, and the input parameters (inventories) of the model (Fig. 2). The variations are impacting the results of the models [22].

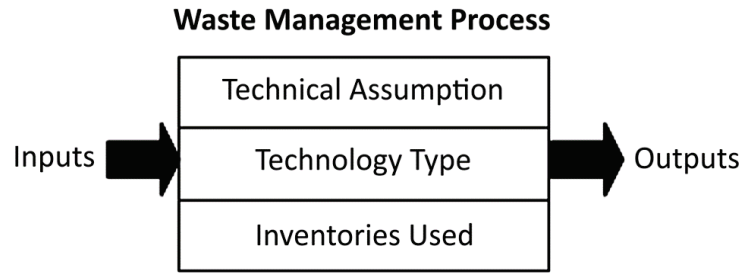

Figure 2 The system boundaries in the waste management process [22]

Gentil et al. [22] explained the technical assumptions, including functional unit, system boundaries, energy modelling, input parameters, and process models. They however made a simplification by excluding in the comparisons the impact assessment (Life Cycle Impact Assessment, LCIA) and life cycle inventories (LCI). Furthermore, collection and transportation processes have been discussed only briefly.

Therefore, a detailed examination of the LCI database of inputs and outputs among LCA models is required. The LCI phase of LCA analysis is an inventory of input/output data of the studied system. Furthermore, a detailed review of the technical assumptions in collection and transportation processes with potential differences must be made. Consequently, this will be discussed in this paper. This review will show why there are differences among models in the field of collection and transportation processes and how to avoid potential obstacles. Because the first and partly the second step of the LCA have already been explained by Gentil et al. [22], this will be omitted in this review. Only technical assumptions of the second phase of LCA (LCI) will be discussed (Fig. 1). Input and output values of models will not be included in this research.

\section{METHODS}

An expanded, methodical survey of international research has been performed in the field of LCA modelling. This research has been carried out with most contemporary network research databases Science Direct, Springer Link, Mendeley, Google Scholar and was performed following a two-step procedure. In the first step the five selected key words ("LCA models", "solid waste", "LCI", "collection", "transportation") in line with the discused topic and headline were selected. The authors chose the above mentioned words because they are most related to the subject area. Such advanced research with key words is quite common in science [e.g. 25, 26]. More key words show also less results and more relevant consequences. On the second stage, we briefly checked all articles and determined multiple criteria to select proper models. The published models have to:

- consider defining waste management process,

- consider defining input and output parameters,

- consider mechanistic or deterministic approaches,

- define the quantities and types of waste fractions,

- define fuel and road vehicles types.

Among these, we found those mentioned in Table 1. There are many articles connected to the models, but only sources marked in bold are used in this research because they clearly define their subject area. The remaining sources show either case studies or linking different system models. Other LCA models were not used either due to limited information, or because only a specific waste management technology was studied. Furthermore, the models that did not include the LCA analysis were not included.

Due to technical, authorial, and study differences connected with the ORWARE model, Sonesson's [27] study will be referred to as ORWARE ${ }^{1996}$, and Sonesson's [28] study ORWARE ${ }^{2000}$. Selected models were divided into mechanistic and deterministic (simple) approaches. The mechanistic transport modelling applies in calculations of a total distance and fuel consumption a significant user-defined input parameter. On the other hand, in the deterministic transport modelling user-defined parameter of total distance and fuel consumption are applied [22, 29]. Waste management processes are within models basically comprised of different activities [30]. For the purpose of our research, the following waste management process will be used: (1) collection, (2) transport, (3) intermediate facilities, (4) recovery, (5) disposal. In this study, only the collection and transportation processes will be compared (Fig. 3). We will also describe waste composition and properties, municipal bins and compare road transportation only.

As seen in Fig. 2, technical assumptions in the waste management process are composed of inputs and outputs of the models. According to Jaunich et al. [31], input parameters are collection schedule, collection rules, collection operation times, labour, economic data, travel speeds, distances, fuel usage rates, garage and office parameters, mixed waste and recyclables storage. For the 
purpose of this research, we will used only a few of the mentioned input parameter in the text and briefly described. The expected outputs will also be mentioned.
Detailed differences among the input and output parameters will be described.

Table 1 List of compared LCA models

\begin{tabular}{|c|c|c|c|c|}
\hline Model & Country & Source & Included in review articles & Approach \\
\hline SWOLF & USA & $\begin{array}{c}\text { Lewis et al. [32], Lewis et al. [33], } \\
\text { Jaunich et al. [31] }\end{array}$ & 1 & Mechanistic \\
\hline LCA-IWM & $\mathrm{EU}$ & Den Boer et al. [30] & Gentil et al. [22] & Mechanistic \\
\hline MSW-DST & USA & Curtis \& Dumas [34] & Gentil et al. [22], Winker \& Bilitewski [23] & Mechanistic \\
\hline EASEWASTE & DK & $\begin{array}{c}\text { Manfredi et al. [35], Chen \& Christensen [36], } \\
\text { Damgaard [29], Technical Univerity of } \\
\text { Denmark [37], Larssen et al. [20] }\end{array}$ & Gentil et al. [22] & Deterministic \\
\hline EASETECH & $\mathrm{DK}$ & Clavreul et al. [38] & 1 & Deterministic \\
\hline EPIC CSR & $\mathrm{CA}$ & EPIC \& CSR [39] & $\begin{array}{c}\text { Gentil et al. [22], Winker \& Bilitewski [23], } \\
\text { Diaz \& Warith [24] }\end{array}$ & Deterministic \\
\hline IWM-2 & UK & Mc Dougall et al. [40] & Gentil et al. [22], Winker \& Bilitewski [23], & Deterministic \\
\hline WASTED & $\mathrm{CA}$ & Diaz \& Warith [24] & Diaz \& Warith [24]/ & Deterministic \\
\hline ORWARE & SW & $\begin{array}{l}\text { Sonesson [27], Sonesson [28], } \\
\text { Eriksson \& Bissailon [41] }\end{array}$ & Gentil et al. [22], Winker \& Bilitewski [23] & $\begin{array}{c}\text { Deterministic and } \\
\text { mechanistic }\end{array}$ \\
\hline
\end{tabular}

(Note: Only sources in bold text are used in this research)
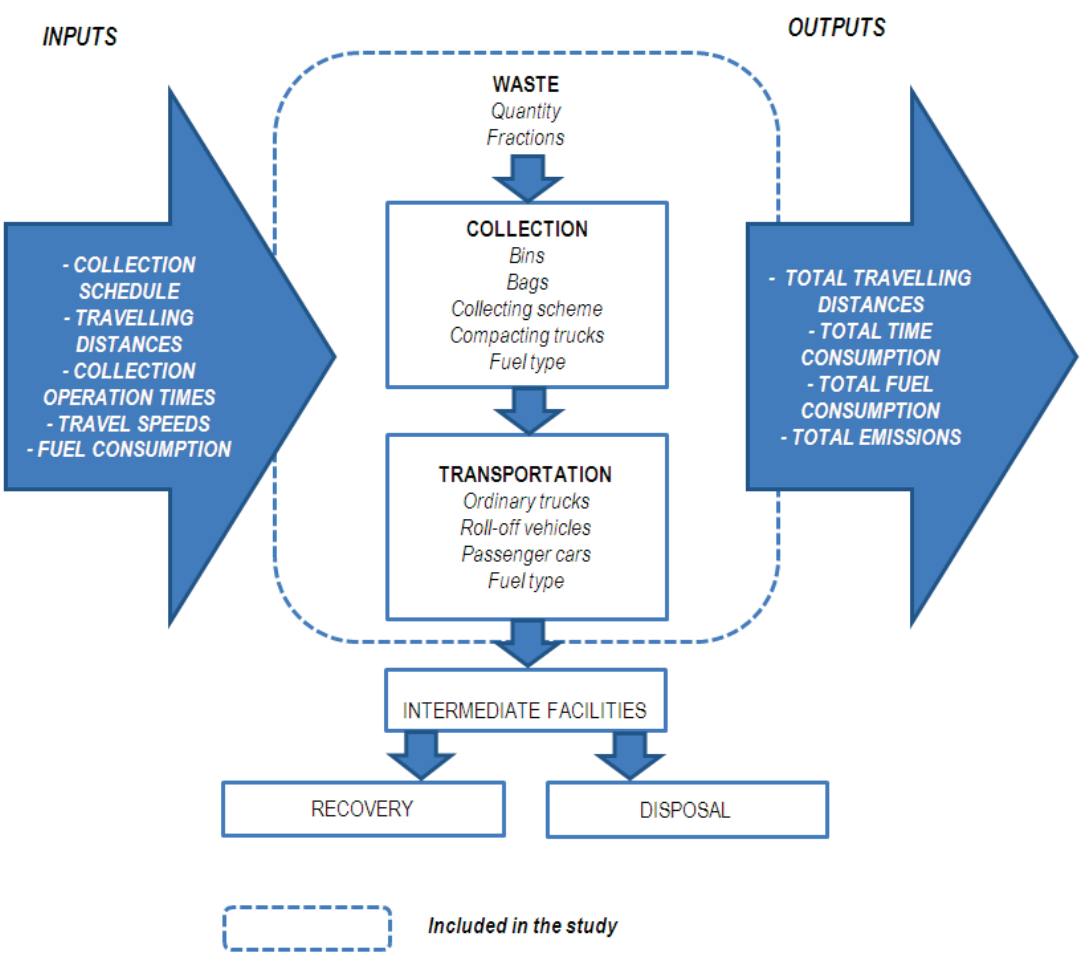

Figure 3 Waste management system

\section{RESULTS}

\subsection{Waste Composition and Properties}

Knowledge about waste composition is the base of precise waste LCA modelling. Namely, waste is defined by different chemical and physical properties of the fractions. Based on these properties they can be used in different processes [22]. EASETECH has the highest number of defined fractions; there are 70 material fractions. Other models have fewer defined fractions (e.g., MSW-DST and EASEWASTE 48, SWOLF 30, ORWARE 22, WASTED 16, LCA-IWM 11, IWM-2 9, EPIC CSR 7) and more limited options. Nevertheless, all the primary waste fractions (paper, plastics, glass and metals) are included in all the models. Among these is also very common organic waste. The fractional compositions of paper (e.g., cardboard, ONP, OCC, office, books etc.), plastics (e.g., bottles, T-HDPE, P-HDPE, PET etc.) or glass (e.g., clear, green and brown) are different among the models. Some models also include rare, less common or harmful fractions, such as LCA-IWM (waste electrical and electronic equipment - WEEE), EPIC CSR (white goods, household hazardous waste, tires), EASEWASTE (batteries), and ORWARE (sewage sludge).

\subsection{Collection Equipment}

Collection and transport are an activity that begins where waste holders leave their fractions to a public service provider, e.g. in bins and bags or sacks. LCA-IWM comprises elemental data on the construction of containers. The decision-maker can choose between five different kinds of containers, nevertheless no inventory is allocated to the assembly of the bins (similar to EASEWASTE, EASETECH and MSW-DST) [22]. In EASEWASTE and EASETECH, the results have been taken from the research 
of Larssen et al. [20] in which bin capacities were dependent on waste fractions (e.g., glass, paper, residual household waste) and collection schemes (e.g., drop off, kerbside, apartment buildings). In LCA-IWM the sacks and bins could have different systems depending on the area of a city. The user can select sacks or small or large bins. In LCA-IWM the lifetime of the waste bins can be specified, similar as in SWOLF and IWM-2. Although in IWM-2 bins and bags are part of the household waste analysis, input values are the material collected in $\mathrm{kg} /$ household/year in kerbside or bring systems. The user can also input the total weight of bins used ( $\mathrm{kg} /$ household), the number of bin washes (household/year) and electrical energy used ( $\mathrm{kWh} /$ bin wash). In the calculation of IWM-2 the warm water for cleaning the containers is also included.. In MSW-DST, the decision-maker can define both the number of bins supplied per household and the price of any bins that are at society cost, which is similar to SWOLF. The rest of the model applications reviewed do not include bins or bags.

\subsection{Travelling Distances}

Collection and transportation are similar activities, which can be expressed as: (1) collection of solid waste in an urban area which is gathered in transfer stations (TS), (2) transportation of the collected solid waste from TS to processing facilities (PF) and disposal facilities (DF) or (3) collection and transportation of solid waste in an urban area, which is gathered in TS or DF. All modes (1, 2 and 3 ) are included in all of the models, except Sonneson ORWARE $^{2000}$ and MSW-DST, which do not include Mode 2. Some of the models include the distance between households to TS/PF/DF only (IWM-2, ORWARE ${ }^{2000}$ ), while the others (ORWARE ${ }^{1996}$, EASETECH, EASEWASTE, SWOLF) prolonged the distance of garage-households-TS/PF/DF-garage. IWM-2 is the only model that covers the distance between households to collection banks with passenger cars. In addition, IWM-2 allowed their users to input the value of their trucks' loads (tonnes). For collection and transportation models, different names of vehicles are used. We can summarise that for Modes 1, and 3 compactors are usually used, and for Mode 2 ordinary trucks or roll-off vehicles are usually used.

All of the models for calculation include at least one input for distance travelling express in kilometres or miles (e.g., total distance, the distance between garage and collection area, etc.). These are deterministic models. In contrast, mechanistic models include more inputs (SWOLF 7, MSW DST 4, ORWARE ${ }^{2000}$ 2). The outputs among them are also very different, e.g., total distance (WASTED), the distance for hauling and collecting (ORWARE ${ }^{2000}$ ), weight per km per day (ORWARE ${ }^{1996}$ ), LCI table (kg/tonne) (EASEWASTE, EASETECH) or time consumption (MSW-DST).

\subsection{Collection Schedule}

The collection schedule in mechanistic models consists of many input parameters (e.g., amount of waste, number of population, number of households, etc.). For example, SWOLF and MSW-DST in this context use participation rates and densities of the waste materials, while others do not. The decision-maker can determine participation element as average percentage of the households involved in the collection and transportation process or input the suitable waste density for selected waste material $\left(\mathrm{kg} / \mathrm{m}^{3}\right)$. In contrast, the deterministic models operate only with one or a few input parameters. For instance, EPIC CSR uses only the amount of waste in tonnes per year as an input, while ORWARE ${ }^{1996}$ uses the average load per vehicle (tonnes) and the number of loads per day.

\subsection{Collection Operation Times}

The deterministic models in this study do not deal with operational times. These use only mechanistic models. While ORWARE ${ }^{2000}$ includes only one input parameter for time consumption (time per stop), MSW DST, and SWOLF also include larger amounts in time input parameters (e.g., travel time to first collection route, (un)loading time at a collection stop, lunch period, break period, etc.). Furthermore, SWOLF offers an option to the decision maker to insert whether the machine's truck is left running amid lunch or pause or not. ORWARE ${ }^{2000}$ 's outputs consist of time for transport, time for driving while collecting and loading time. Because of the larger amounts of inputs, MSW-DST and SWOLF's outputs are also much larger. In addition to those mentioned for ORWARE ${ }^{2000}$, MSW-DST and SWOLF include time for loading, time for unloading, time for lunch, time for breaks, using different units.

\subsection{Travel Speeds}

In the LCA models, only the mechanistic models include travel speeds. The travel speeds in these models are either narrowly (ORWARE ${ }^{2000}$ ) or broadly (MSW-DST, SWOLF) described. For example, ORWARE ${ }^{2000}$ as input includes the average speed for collecting and hauling $(\mathrm{km} / \mathrm{h})$. MSW-DST and SWOLF include much more detailed and larger input parameters (e.g., average travel speed among starting point and beginning of collection route, average travel speed of collection stops, etc.). MSW-DST uses (mph) as an input while ORWARE ${ }^{2000}$ and SWOLF use $(\mathrm{km} / \mathrm{h})$.

The outputs obtained during calculation in these models are very different. While ORWARE ${ }^{2000}$ outputs are time for hauling and collecting only, MSW-DST outputs parameters additionally include those travel times and travelled distances. While ORWARE ${ }^{2000}$ are passing time for hauling and collecting (h/year) only, MSW-DST outputs parameteres include the travelled distance in addition to travel times.

\subsection{Fuel Consumption}

The fuel consumption is connected with different criteria, e.g. type of road (e.g. plane, uphill, downhill), type of fuel (e.g. diesel, gasoline), type of vehicle (e.g. light, medium, heavy), manner of driving (e.g. acceleration, speed, breaking), type and weight of waste (e.g. mixed packaging is much lighter than mixed municipal waste), 
(non)automatic container-lifting mechanism [37] and also wind direction [54].

There are a few types of fuel consumption in LCA models. While all include the most conventional diesel fossil fuel, some of them used less harmful alternatives. For instance, petrol (MSW-DST, IWM-2), natural gas (EPIC CSR), compressed natural gas (CNG) (SWOLF), or liquefied natural gas (LNG) (WASTED). The inputs for fuel consumption among models are very different. While the deterministic models include only a total fuel consumption parameter, the mechanistic ones handle more inputs. While ORWARE ${ }^{2000}$, MSW-DST. and LCA-IWM deal with fuel consumption when the vehicle travels, stops, or idles, SWOLF includes average fuel consumption, as well as and fuel consumption in urban and highway.

The outputs of the models are either total fuel usage (MSW-DST, SWOLF), energy consumption (ORWARE ${ }^{1996}$, ORWARE $^{2000}$, WASTED, MSW-DST) or emissions (MSW-DST, EPIC CSR, IWM-2, WASTED, SWOLF). While early models include emission of fuel combustion only (ORWARE ${ }^{1996}$ ), more recent models also used emissions of fuel pre-combustion (production) (EASEWASTE, EASETECH, MSW-DST, SWOLF).

\section{DISCUSSION AND CONCLUSION}

Nine waste models on the LCA basis were analysed to compare the technical assumptions in the collection and transportation processes. We look more precisely into inputs/outputs of the system within these processes. With this review we can better understand the results and compare the sub-models. As can be seen, not all of the inputs and outputs presented in Fig. 3 were included in all of the models. The main reason is a deterministic or mechanistic approach that makes larger differences among models and makes any comparison more confusing and complicated.

Deterministic transport modelling uses very narrow collecting schedule inputs. While it provides users with the largest amount of different material fractions (EASETECH), only one or few input parameters for the total distance and fuel consumption can be inserted. Furthermore, unlike mechanistic models, deterministic models do not include travel speed or collection operation times; therefore, they cannot be used for detailed cost calculations in life cycle costing (LCC) $[42,43]$. LCC has a consistent methodology with LCA and includes conventional [44, 45], environmental [45, 46, 47, 48] or/and societal $[45,49]$ variants. Some studies on waste management field are remarkable including more LCC variants [45] or linking both LCA and LCC tools [e. g. 45, 50].

Mechanistic models use a vast number of userspecified input parameters when calculating the entire distance, fuel consumption, or the collection operation time of the vehicles in the system.

Table 2 Time consumption in Kostak Company

\begin{tabular}{|c|c|c|c|c|c|c|}
\hline \multicolumn{3}{|c|}{ Parameters } & $\begin{array}{c}\text { Average time } \\
\text { needed }\end{array}$ & Unit & $\begin{array}{l}\text { Machine is } \\
\text { running? }\end{array}$ & $\begin{array}{c}\text { Num. of } \\
\text { measurements }\end{array}$ \\
\hline \multirow{4}{*}{$\begin{array}{l}\text { Washing bins } \\
\text { (biodegradable } \\
\text { waste, } 200201)^{(1)}\end{array}$} & \multirow{2}{*}{ First } & 1201 & 37 & $\mathrm{sec}$ & Yes & 25 \\
\hline & & 2401 & 44 & sec & Yes & 3 \\
\hline & \multirow{2}{*}{ Second (if needed) } & 1201 & 37 & sec & Yes & 13 \\
\hline & & 2401 & 30 & sec & Yes & 1 \\
\hline \multirow{8}{*}{ Emptying bins ${ }^{(1),(2)}$} & \multirow{2}{*}{ Mixed packaging (15 0106$)$} & 1201 & 9 & sec & Yes & 41 \\
\hline & & 1100 & 18 & sec & Yes & 18 \\
\hline & Paper and cardboard packaging (15 0101$)$ & 11001 & 12 & $\mathrm{sec}$ & Yes & 25 \\
\hline & \multirow{3}{*}{ Biodegradable waste (20 0201$)$} & 120 & 14 & sec & Yes & 15 \\
\hline & & 240 & 15 & $\mathrm{sec}$ & Yes & 16 \\
\hline & & $770-1100$ & 20 & $\mathrm{sec}$ & Yes & 10 \\
\hline & \multirow{2}{*}{ Mixed municipal waste (20 0301$)$} & 120 & 14 & sek & Yes & 2 \\
\hline & & 1100 & 12 & sek & Yes & 35 \\
\hline \multicolumn{3}{|c|}{ Fueling of the vehicle ${ }^{(1)}$} & 15 & $\min$ & No & 9 \\
\hline \multicolumn{3}{|c|}{ Manual cleaning of bins surfaces (drop off collecting system, $30-50 \mathrm{~m}^{2}$ ) } & 25 & $\begin{array}{c}\text { min per } \\
\text { cleaning with } 1 \\
\text { person }\end{array}$ & No & 10 \\
\hline \multicolumn{3}{|c|}{ Cleaning and maintanance of the vehicle ${ }^{(1)}$} & 60 & $\begin{array}{c}\text { min per every } \\
40 \text { hours }\end{array}$ & No & 10 \\
\hline \multicolumn{3}{|c|}{ Vehicle unloading at intermediate facility ${ }^{(1)}$} & 20 & $\min$ & Yes & 15 \\
\hline \multirow[t]{2}{*}{$\begin{array}{l}\text { Waste loading with } \\
\text { loader crane } \\
(3)\end{array}$} & \multicolumn{2}{|c|}{ Fractions: wood packaging, (15 0103$)$, wood (20 01 38) } & 45 & $\begin{array}{c}\text { min per } 30 \mathrm{~m}^{3} \\
\text { container }\end{array}$ & Yes & 5 \\
\hline & \multicolumn{2}{|c|}{$\begin{array}{l}\text { Paper and cardboard packaging (15 } 0101) \text {, mixed } \\
\text { packaging (15 01 06) }\end{array}$} & 55 & $\begin{array}{c}\text { min per } 30 \mathrm{~m}^{3} \\
\text { container }\end{array}$ & Yes & 10 \\
\hline $\begin{array}{l}\text { Waste loading with } \\
\text { wheel loader }{ }^{(4)}\end{array}$ & \multicolumn{2}{|c|}{ Fractions: wood (20 0138$)$ and mixed packaging (15 01 06) } & 450 & $\begin{array}{l}\text { sec per } 30 \mathrm{~m}^{3} \\
\text { container }\end{array}$ & Yes & 8 \\
\hline
\end{tabular}

Notes: (1) Rear load garbage truck. (2) Measurements of emptying plastic bins included an automatic lifting of the container from the ground, emptying and descending to the ground. The stuffing of the bins with waste material was similar in all cases, i.e. 1/2 of maximum. (3) Hiab. (4) Wheel loader, volume bucket $6 \mathrm{~m}^{3}$. (5) 1501 01, 1501 03, 1501 06, 2001 38, 2002 01, 200301 - six-digit codes of waste according to Commision Decision (2014) [53].

However, these models do not include time consumption for fuelling, washing bins, manual cleaning of container surfaces, the cleaning or maintenance of the vehicle, etc., which also takes significant time in the collection and transportation process. Furthermore, in the existing models in intermediate facilities (e.g., transfer stations, treatment facilities etc.), no time or energy consumption for waste handling is included (e.g., waste loading with loader crane or wheel loader on truck etc.). Waste manipulation is also one of the crucial elements of solid waste operations. With the aim of making future models more precisely calculating the time and energy consumption, the measurements were taken in the Kostak Company. The public service Kostak carries out the public 
service of municipal waste collection in municipalities Krško and Kostanjevica na Krki, Slovenia, at $345 \mathrm{~km}^{2}$, supplying 11,000 households and collecting about 10,500 tons of waste annually. Statistical numbers are obtained through the latest vehicle technology and manipulation tools and are described in Tab. 2. There are some additional parameters, e.g.emptying bins for different kind of waste fractions and bins capacity, which is not included in the latest literature, as well as the option whether a machine is running in activity or not. All these provide modern results of measurements which can work as valuable inputs in the LCI databases of LCA/LCC models.

The research reveals that any of the models could use bio fuels. Using renewable sources in transportation is not related with harmful effects on the biosphere [51, 52], if they are obtained sustainably, and is in line with the Directive 2009/28/EC [53]. Because fuels of petrified remains are producing negative impact on the environment due to air pollution, environmentally friendly sources should also be included in the future waste LCA modelling.

Former LCA models used metal or plastic bins and sacks. They did not take into consideration bioplastic. Since it was found out that bioplastic is more environmentally sustainable than ordinary plastic or metal, reusable and rugged [26], it is appropriate material which can substitute conventional materials.

Both deterministic and mechanistic models are mostly adjusted to local conditions (e.g., road type, speed limits, population density, altitude, etc.) for collecting compressible fractions with garbage trucks and emptying of containers with hydraulic/mechanic power or using large ordinary and roll-on trucks for transport fractions from collection facilities to treatment plants. Nevertheless, it could not take into account technology (e.g. loader crane, van etc.) for kerbside collecting of different kinds of waste (e.g. WEEE, hazardous, oils, wood etc.), which are becoming increasingly more important in the technosphere and the biosphere and cannot be compacted like other waste. Volumes of WEEE, waste wood from households and hazardous waste are rising in the EU. While quantities of hazardous waste rose from $111 \mathrm{~kg}$ per capita in 2008 to $124 \mathrm{~kg}$ per capita in 2016 , amounts of waste wood from househols rose from 2,390,000 tons in 2004 to 5,220,000 tons in 2016. WEEE are also fast growing waste material, for instance in Croatia they rise more than one kg per capita per year and in 2016 they reached $8,42 \mathrm{~kg}$ per capita in 2016. similar to Lichenstein $(13,91 \mathrm{~kg}$ per capita). The numbers for France and the Czech Republic are a bit lower $($ France $=9,97 \mathrm{~kg}$ per capita; the Czech Republic $=8,08 \mathrm{~kg}$ per capita)[6]

Furthermore, due to mechanistic models permittin only restricted user modification of model parameters there is a need to form suitable inputs (e.g., rearranging existing collection schedules, travelling distances and speeds, collection operation time, fuel consumption etc.) for other kinds of transport modes and model accommodated to the selected vehicle and desired waste fractions.

Special emphasis in future LCA models are also further quantitative measurements which can in line with mechanistic approach serve as valuable inputs in LCI databases LCI, thus provide more precise calculations and accurate connections with the LCC. Detailed information in the LCI related to detail time consumption (Tab. 2) with the use of bottom-up principle enables detailed calculation of costs (required number of workers, teams, technology equipment etc.), based on the time spent. Besides that, important factors are accurate fuel consumption and emissions, especially when taken into account whether the engine is running or not.

In a time when raw materials became expensive and the stocks scarcer, there is need to take into account other kinds of waste, different and newer collecting technologies and secondary resource. Therefore, as Winkler \& Bilitevski [21] stated, most important is that the further evolution of the models carryies on.

\section{Acknowledge}

Authors would like to thank the anonymous reviewers for their valuable comments, which have helped in improving the quality of the paper. In addition, the authors would like to thank the KOSTAK Company for their permission to share the time measurements.

\section{REFERENCES}

[1] Evans, A. (2010). Resource scarcity, climate change and the risk of violent conflict. Center or international cooperation. New York University. Retrieved from: https:/openknowledge.worldbank.org/bitstream/handle/109 86/9191/WDR2011_0024.pdf?sequence $=2 \&$ isAllowed $=y$

[2] World Bank (2018). World Bank Commodities Price Forecast - released April 24, 2018. Retrieved from: http://pubdocs.worldbank.org/en/458391524495555669/C MO-April-2018-Forecasts.pdf

[3] Bilitewski, B. (2012). The Circular Economy and its Risks. Waste Management, 32, 1-2. https://doi.org/10.1016/j.wasman.2011.10.004

[4] Ellen MacArthur Foundation (2014). Towards the Circular Economy: Accelerating the scale-up across global supply chains. Retrieved from: https://www.ellenmacarthurfoundation.org/assets/download s/publications/Towards-the-circular-economy-volume-3.pdf

[5] Reh, L. (2013). Process engineering in circular economy. Particuology, 11, 119-133. https://doi.org/10.1016/j.partic.2012.11.001

[6] Eurostat (2019). Waste statistics. Retrieved from: http://ec.europa.eu/eurostat/statistics-explained/index.php/ Waste_statistics

[7] Kutnar, A., Krč, J., Krajnc, N., Piškur, M., Tavzes, Č., \& Humar, M. (2012): Life cycle analysis (LCA) - objective assessment of the environmnetal requirements in the frame of green public procurement (In Slovene). Les Wood, 64(6), 181-186.

[8] Vjestica, S., Budak, I., Kljajin, M., Vukelic, D., Milanovic, B., Milankovic, D., \& Hodolic, J. (2014). Model for analysis of environmental impacts of production processes in flooring industry based on LCA. Tehnicki vjsnik, 21(3), 457-466.

[9] Büyükozkan, G. \& Karabulut, Y. (2018). Sustainability performance evaluation: Literature review and future directions. Journal of Environmental Management, 217, 253-267. https://doi.org/10.1016/j.jenvman.2018.03.064

[10] Zhu, L. \& Hu, D. (2017). Sustainable Logistics Network Modeling for Enterprise Supply Chain. Mathematical Problems in Engineering, Vol. 2017. https://doi.org/10.1155/2017/9897850

[11] ISO 14040 (2006). Environmental management - Life cycle assessment - Principles and framework. International Organisation for Standardisation (ISO), Geneve. 
[12] ISO 14044 (2006). Environmental management - Life cycle assessment - Requirements and guidelines. International Organisation for Standardisation (ISO), Geneve.

[13] Laurent, A., Clavreul, J., Bernstad, A., Bakas, I., Niero, M. Gentil, E., Christensen, T. H., \& Hauschild, M. Z. (2014). Review of LCA studies of solid waste management systems - Part I: Lessons learned and perspectives. Waste Management, 34, 573-588. https://doi.org/10.1016/j.wasman.2013.10.045

[14] Laurent, A., Clavreul, J., Bernstad, A., Bakas, I., Niero, M., Gentil, E., Christensen, T. H., \& Hauschild, M. Z. (2014). Review of LCA studies of solid waste management systems - Part II: Methodological guidance for a better practice. Waste Management, 34, 589-606. https://doi.org/10.1016/j.wasman.2013.12.004

[15] GaBi (2018). Product Sustainability Performance. Retrieved from: http://www.gabi-software.com/ce-eu-english/ overview/product-sustainability-performance/

[16] Vinci, G., D'Ascenzo, F., Esposito, A., Musarra, M., Rapa., M., \& Rocchi, A. (2019). A Sustainable innovation in the Italian glass production: LCA and Eco-Care matrix evaluation. Journal of Cleaner Production, 223, 587-595. https://doi.org/10.1016/j.jclepro.2019.03.124

[17] Ecoinvent 3.0 (2013). Swiss Centre for Life Cycle Inventories, Dübendorf, Switzerland

[18] Bernstad, A., Jansen, J., \& Aspegren (2011). Life cycle assessment of a household solid waste source separation programme: a Swedish case study. Waste Manag Res, 29, 1027. https://doi.org/10.1177/0734242X11406170

[19] Merrild, H., Larsen, A. W., \& Christensen, T. H. (2012). Assessing recycling versus incineration of key materials in municipal waste: The importance of efficient energy recovery and transport distances. Waste Management, 32 1009-1018. https://doi.org/10.1016/j.wasman.2011.12.025

[20] Larsen, A. W., Vrgoc, M., \& Christensen, T. H. (2009). Diesel consumption in waste collection and transport and its environmental significance. Waste Management \& Research, 27, 652-659. https://doi.org/10.1177/0734242X08097636

[21] Laurijssen, J., Marsidi, M., Westenbroek, A., Worrell, E., \& Faaij, A. (2010). Paper and biomass for energy? The impact of paper recycling on energy and $\mathrm{CO}_{2}$ emissions. Resources, Conservation and Recycling, 54, 1208-1218. https://doi.org/10.1016/j.resconrec.2010.03.016

[22] Gentil, E., Damgaard, A., Hauschild, M., Finnveden, G., Barlaz, M., Thorneloe, S., Kaplan, P. O., Eriksson, O., Matsui, Y., Ii, R., Thomas, B., Jones, R. \& Christensen, T. H. (2010). Models for waste life cycle assessment: Review of technical assumptions. Waste Management, 30, 26362648. https://doi.org/10.1016/j.wasman.2010.06.004

[23] Winkler, J. \& Bilitewski, B. (2007). Comparative evaluation of life cycle assessment models for solid waste management. Waste Management, 27, 1021-1031. https://doi.org/10.1016/j.wasman.2007.02.023

[24] Diaz, R. \& Warith, M. (2006). Life-cycle assessment of municipal solid wastes: Development of the WASTED model. Waste Management, 26, 886-901. https://doi.org/10.1016/j.wasman.2005.05.007

[25] Pejić, V., Lerher, T., Jereb, B., \& Lisec, A. (2016). Lean and Green Paradigms in Logistics: Review of Published Research. Promet - Traffic \& Transportation, 28(6). https://doi.org/10.7307/ptt.v28i6.2078

[26] Gardas, B. B., Raut, R. D., \& Nerkhede, B. (2019). Identifying critical success factors to facilitate reusable plastic packaging towards sustainable supply chain management. Journal of Environmental Management, 236, 81-92. https://doi.org/10.1016/j.jenvman.2019.01.113

[27] Sonesson, U. (1996). Modelling of the compost and transport process in the ORWARE simulation model. Institutionen för lantbruksteknik. Swedish University of Agricultural
Sciences Department of Agricultural Engineering. Uppsala, ISSN 0283-0086.

[28] Sonesson, U. (2000). Modelling of waste collection - a general approach to calculate fuel consumption and time. Waste Manage. Res., 18, 115-123. https://doi.org/10.1177/0734242X0001800203

[29] Damgaard, A. (2010). Implementation of life cycle assessment models in solid waste. management. Department of Environmental Engineering. Technical University of Denmark. PhD Thessis.

[30] Den Boer, E., Den Boer, J. \& Jager, J. (2007). LCA-IWM: a decision support tool for sustainability assessment of waste management systems. Waste Management, 27, 1032-1045. https://doi.org/10.1016/j.wasman.2007.02.022

[31] Jaunich, M. K, Lewis, J. W., DeCarolis, J. F. Barlaz, M. A., Bertelt-Hunt, S. L., Jones, E. G., \& Jaikumar, R. (2016). Characterization of municipal solid waste collection operations. Resources, Conservation and Recycling, 114, 92102. https://doi.org/10.1016/j.resconrec.2016.07.012

[32] Lewis, J. W., Barlaz, M. A., DeCarolis, J. F., \& Ranjithan, S. R. (2013). A generalized multistage optimization modeling framework for life cycle assessment-based integrated solid waste management. Environmental Modelling \& Software, 50, 51-65. https://doi.org/10.1016/j.envsoft.2013.08.007

[33] Lewis, J. W., Barlaz, M. A., DeCarolis, J. F., \& Ranjithan, S. R. (2014). Systematic Exploration of Efficient Strategies to Manage Solid Waste in U.S. Municipalities: Perspectives from the Solid Waste Optimization Life-Cycle Framework (SWOLF). Environ. Sci. Technol., 48, 3625-3631. https://doi.org/10.1021/es500052h

[34] Curtis, E. M. \& Dumas, R. D. (2000). A spreadsheet process model for analysis of costs and life-cycle inventory parameters associated with collection of municipal solid waste. Retrieved from: http://www4.ncsu.edu/ jwlevis/ DST Collection.pdf

[35] Manfredi, S., Niskanen, A., \& Christensen, T. H. (2009). Environmental assessment of gas management options at the Old Ämmässuo landfill (Finland) by means of LCAmodeling (EASEWASTE). Waste Management, 29, 15881594. https://doi.org/10.1016/j.wasman.2008.10.005

[36] Chen, D. \& Christensen, T. H. (2010). Life-cycle assessment (EASEWASTE) of two municipal solid waste incineration technologies in China. Waste Manage. Res., 28, 508-519. https://doi.org/10.1177/0734242X10361761

[37] Technical University of Denmark (2012). Easewaste - User manual. Retrieved from: http://documents.er.dtu.dk/ Projects/Easewaste/Shared\%20Files/pdf/120412\%20\%20Documanual\%20-\%20Full.pdf

[38] Clavreul, J., Baumeister, H., Christensen, T. H., \& Damgaard, A. (2014). An environmental assessment system for environmental technologies. Environmental Modelling \& Software, Volume. 60, 18-30 https://doi.org/10.1016/j.envsoft.2014.06.007

[39] EPIC \& CSR (2004). Integrated Solid Waste Management Tools:Measuring the Environmental Performance of Waste Management Systems. Environment and Plastics Industry Council and Corporations supporting recycling.

[40] McDougall, F., White, P. R., Franke, M. \& Hindle, P. (2001). Integrated Solid Waste Management: A Life Cycle Inventory. Second ed. Oxford, UK. https://doi.org/10.1007/BF02978794

[41] Eriksson, O. \& Bisaillon, M. (2011). Multiple system modelling of waste management. Waste Management, 31 , 2620-2630. https://doi.org/10.1016/j.wasman.2011.07.007

[42] European Commision (2019). Life-cycle costing. Retrieved from: $\mathrm{http}: / / \mathrm{ec}$.europa.eu/environment/gpp/lcc.htm

[43] De Menna, F., Dietershagen, J., Loubiere, M., \& Vittuari, M. (2018). Life Cycle Costing of food waste: A review of methodological approaches. Waste Management, 73, 1-13. https://doi.org/10.1016/j.wasman.2017.12.032 
[44] Groot, J., Bing, X., Bos-Brouwers, H., \& BloemhofRuwaard, J. (2014). A comprehensive waste collection cost model applied to post-consumer plastic packaging waste. Resources, Conservation and Recycling, 85, 79-87. https://doi.org/10.1016/j.resconrec.2013.10.019

[45] Martinez-Sanchez, V., Kromann, M. A., \& Astrup, T. F. (2015). Life cycle costing of waste management systems: overview, calculation principles and case studies. Waste Manag., 36, 343-355. https://doi.org/10.1016/j.wasman.2014.10.033

[46] Rigamonti, L., Sterpi, I., \& Grosso, M. (2016). Integrated municipal waste management systems: An indicator to assess their environmental and economic sustainability. Ecol. Indic., 60, 1-7. https://doi.org/10.1016/i.ecolind.2015.06.022

[47] Willersinn, C., Mouron, P., Mack, G., \& Siegrist, M. (2017). Food loss reduction from an environmental, socio-economic and consumer perspective - the case of the Swiss potato market. Waste Manag. 59, 451-464. https://doi.org/10.1016/j.wasman.2016.10.007

[48] Bong, C. P.-C., Goh, R. K. Y., Lim, J.-S., Ho, W. S., Lee, C.-T., Hashim, H., Abu Mansor, N. N., Ho, C. S., Ramli, A. R., \& Takeshi, F. (2017). Towards low carbon society in Iskandar Malaysia: implementation and feasibility of community organic waste composting. Journal of Environmental Management Volume, 203, Part 2, 679-687. https://doi.org/10.1016/j.jenvman.2016.05.033

[49] Woon, K. S. \& Lo, I. M. C. (2016). An integrated life cycle costing and human health impact analysis of municipal solid waste management options in Hong Kong using modified eco-efficiency indicator. Resour. Conserv. Recycl., 107, 104114. https://doi.org/10.1016/j.resconrec.2015.11.020

[50] Grimaud, G., Laratte, B., \& Perry, N. (2017). To transport waste or transport recycling plant: Insights from life-cycle analysis. Matériaux \& Techniques, 105(5-6), Society and Materials (SAM11). https://doi.org/10.1051/mattech/2018016

[51] Kiss, A. A., Dimian, A. C., \& Rothenberg, G. (2008). Biodiesel by catalytic reactive distillation powered by metal oxides. Energy and Fuels Volume, 22(1), 598-604. https://doi.org/10.1021/ef700265y

[52] El Khatib, S. A., Hanafi, S. A., Barakat, Y., \& Al-Amrousi, E. F. (2018). Hydrotreating rice bran oil for biofuel production. Egytian Journal of Petroleum, 27(4), 13251331. https://doi.org/10.1016/j.ejpe.2018.08.003

[53] European Commision (2009). Directive 2009/28/EC of the European Parliament and of the Council of 23 April 2009 on the promotion of the use of energy from renewable sources and amending and subsequently repealing Directives 2001/77/EC and 2003/30/EC. Official Journal of the European Union, L 140/16.

[54] Nevrlý, V., Šomplák, R., Gregor, J., Pavlas, M., \& Klemeš, J. J. (2018). Impact assessment of pollutants from wasterelated operations as a feature of holistic logistic tool. Journal of Environmental Management, 220, 77-86. https://doi.org/10.1016/j.jenvman.2018.05.003

[55] Commission Decision (2014). Commision Decision of 18 December 2014 amending Decision 2000/532/EC on the list of waste pursuant to Directive 2008/98/EC of the European Parliament and of the Council (2014/955/EU). Official Journal of the European Union L 370/44.

\section{Contact information:}

Boštjan VIMPOLŠEK, MSc

Kostak Company,

Leskovška cesta 2a, 8270 Krško, Slovenia

bostjan.vimpolsek@kostak.si

Borut JEREB, Dr. Sc

University of Maribor, Faculty of Logistics, Mariborska cesta 7, 3000 Celje, Slovenia borut.jereb@um.si

Tone LERHER, Dr. Sc.

University of Maribor, Faculty of Logistics, Mariborska cesta 7, 3000 Celje, Slovenia Tone.lerher@um.si

Andreja KUTNAR, Dr. Sc

University of Primorska, FAMNIT

Glagoljška 8, 6000 Koper, Slovenia andreja.kutnar@upr.si

Andrej LISEC, Dr. Sc

University of Maribor, Faculty of Logistics, Mariborska cesta 7, 3000 Celje, Slovenia andrej.lisec@um.si 